of stoichiometric phases of the type $(\mathrm{Cr}$, $\mathrm{Fe})_{23} \mathrm{C}_{6}$ or $(\mathrm{Cr}, \mathrm{Fe})_{7} \mathrm{C}_{3}$, where iron substitutes chromium in these stable carbides.

A knowledge of the thermodynamic properties of the elements, stoichiometric compounds and solution phases, in stable or metastable states then allows the determination of phase relationships either for stable or metastable equilibria. The compositions of the phases in equilibrium at a given temperature and pressure are obtained by minimizing the Gibbs energy with respect to the independent variables, or by resolving a set of equations expressing the equality of the chemical potentials of the different constituents in these phases.

\section{Motivation}

The main interest in phase diagram calculations using a thermodynamic approach is that from a limited amount of information concerning the mixing properties of solution phases, equilibrium phase relationships and compositions can be established from a limited number of experiments. Successful results have been obtained in applying such calculations to crystal growth of semiconductors by liquid phase epitaxy, or to directionally solidified in situ super-alloy composites. Different representations can be used; isothermal sections of ternary systems, or vertical cuts corresponding to a quasi-binary section defining temperature versus metallic ratio, are the most classical ways of representation of equilibrium diagrams. A simple geometrical transformation can be made to plot the phase limits in a chemical potential (logarithm of the partial pressure or the activity of any of the constituents) versus atom ratio diagram. These types of diagram have the advantage of allowing phase boundaries of an isothermal section of a ternary system to be plotted in a rectangular diagram, similar to that used to represent binary systems.

Problems arise of course when the number of constituents is greater than three, but numerical techniques for calculating phase boundaries in higher order systems are now being developed in many laboratories together with graphical methods for representing the results.

\section{Basic Data Sources}

To provide the best possible phase diagram it is essential, as mentioned above, to obtain consistent sets of thermochemical and phase diagram data. Members of the international Calphad project produce on a regular basis, assessed thermodynamic data and phase diagrams for selected binary and ternary systems.

Computer based databanks providing thermochemical data for inorganic substances are also in operation in Europe. The scientific group Thermodata Europe, which is formed by members of AERE, Harwell
(UK) NPL, Teddington (UK), RheinischWestfälische Technische Hochschule, Aachen (FRG), Royal Institute of Technology, Stockholm (S), IRSID, Maizières les Metz (F), L.T.P.C.M. - Institut National Polytechnique and Thermodata (in France) at Saint-Martin-d'Hères (F) offers critically assessed and up-dated data and in certain cases also, an on-line service.

A more ambitious goal is assigned to Codata Task Group on the Systematization and Internationalization of Thermodynamic Data. This Task Group is charged with the development of a world-wide system for producing self-consistent tables, whether they originate from data centres or from groups with special interests in special areas. The task involves systematic analysis of the methodology of obtaining such tables for special classes of substances (alloys, aqueous solutions...).

These international efforts reflect the need to obtain compiled and assessed data for given substances and to develop interactive procedures to facilitate data bank operations. At the same time, great attention should be paid to educating the technical and scientific community to the efficacy of this development.

\section{BIBLIOGRAPHY}

1. Meijering J.L., Acta Met. 5 (1957) 275.

2. Kaufman L. and Bernstein H., Computer Calculations of Phase Diagrams (Academic Press, N.Y.) 1970.

3. Hillert M., Phase Transformations (A.S.M. Metals Park, Ohio) 1970, p. 181.

4. Nishizawa T., Hasebe M. and Ko M., Acta Met. 27 (1979) 817 and Proc. CALPHAD VIII (Stockholm) 1979.

5. Zener C., Trans. AIME 203 (1955) 619.

6. Hillert M., Wada T. and Wada H., J. Iron Steel Inst. 205 (1967) 539.

7. Kikuchi R., Acta Met. 25 (1977) 195.

8. Kikuchi R., de Fontaine D., Murakami M. and Nakamura T., Acta Met. 25 (1977) 207.

9. Van der Rest J., Gautier F. and Brouers F., J. Phys. F. Metal Phys. 5 (1975) 2283.

10. Boom R., de Boer F.R. and Miedema A.R., J. Less Common Metals 46 (1976) 46.

11. Pettifor D.G., Phys. Rev. Lett. 42 (1979) 13 , 846.

12. Hildebrand J.H., J. Am. Chem. Soc. 51 (1929) 51.

13. Guggenheim E.A., Mixtures (Clarendon Press, Oxford) 1952.

14. Mathieu J.C., Durand F. and Bonnier E., J. Chim. Phys. 62 (1965) (11-12) a) 1289, b) 1297.

15. Lupis C.H.P. and Elliott J.F., Acta Met 15 (1967) 265

16. Ansara I., Intern. Metals Review 1 (1979) 20.

\title{
Atomic Spring in Heidelberg
}

The First European Conference on Atomic Physics (ECAP) of the European Physical Society will take place in Heidelberg, FRG, from 6 to 10 April, 1981. All Sections of the Atomic Physics Division will be represented: Atomic Spectroscopy, Molecular Physics, Electron and Atomic Collisions as well as Chemical Physics. The Conference has been initiated with the aim of bringing more closely together the various branches of atomic and molecular physics, existing in Europe, underlining the common scientific aspects and enhancing the cooperation between European laboratories. In order to support this idea the national physical societies have dispensed with their own scientific meetings in 1981 in favour of ECAP.

The Atomic Physics Division is responsible for the scientific organization of the meeting; G. zu Putlitz (University of Heidelberg and Gesellschaft für Schwerionenforschung, Darmstadt) is Conference Chairman. The scientific programme calls for five morning sessions and four afternoon sessions. In each morning session two plenary lectures will be given followed by two parallel sessions with two progress reports each. The plenary lectures will be of general interest for all participants. They should, as well as the progress reports, deal with subjects in the fields mentioned above so that young physicists and students get acquainted with the problems.
The programme discussion concentrates on the following focal points: weak interactions between atoms and molecules, laser chemistry, reactive scattering and chemical ionization, atomic and molecular collision processes in combination with selective excitation of states, coincidence experiments, scattering processes in high fields, photochemistry in the upper atmosphere, high resolution atomic and molecular spectroscopy in particular with respect to fundamental questions of atomic physics, the use of accelerators and synchrotron radiation in atomic and molecular physics, atomic physics in heavy ions. The afternoon sessions will be devoted to contributed papers with sessions for oral as well as poster presentation.

Conference abstracts are limited to two pages and have to be typed on forms in order to be directly reproducible. The forms are obtainable from the secretary's office. Deadline is 1 February, 1981. The conference address is:

European Conference on Atomic Physics (ECAP), Professor Dr. G. zu Putlitz, Physikalisches Institut der Universität Heidelberg, Philosophenweg 12, D-6900 Heidelberg. Telephone (6221) 569-211, -212, -213; Telex 461515 unihd d.

Two Conference Circulars are mailed already and can be ordered from the abovementioned address.

\section{R. Neumann, Heidelberg}

